\title{
Methionine synthase reductase polymorphisms are associated with serum osteocalcin levels in postmenopausal women
}

\author{
Duk Jae Kim, Byung Lae Park², \\ Jung-Min Koh", Ghi Su Kim ${ }^{1}$, \\ Lyoung Hyo $\mathrm{Kim}^{2}$, Hyun Sup Cheong', \\ Hyoung Doo Shin ${ }^{2}$, Jung-Min Hong ${ }^{3}$, \\ Tae-Ho Kim ${ }^{3}$, Hong-In Shin ${ }^{3,4}$, \\ Eui Kyun Park ${ }^{3,4,6}$ and Shin-Yoon Kim ${ }^{3,5,6}$ \\ ${ }^{1}$ Division of Endocrinology and Metabolism \\ University of Ulsan College of Medicine \\ Asan Medical Center \\ Seoul 138-736, Korea \\ ${ }^{2}$ Department of Genetic Epidemiology \\ SNP Genetics, Inc. \\ Seoul 110-834, Korea \\ ${ }^{3}$ Skeletal Diseases Genome Research Center \\ Kyungpook National University Hospital \\ Daegu 700-412, Korea \\ ${ }^{4}$ Department of Pathology, School of Dentistry \\ ${ }^{5}$ Department of Orthopaedic Surgery \\ School of Medicine, Kyungpook National University \\ Daegu 700-712, Korea \\ ${ }^{6}$ Corresponding authors: Tel, 82-53-420-4995 (EK Park); \\ 82-53-420-5635 (SY Kim); \\ Fax, 82-53-427-4918 (EK Park); 82-53-422-6605 (SY Kim); \\ E-mail, epark@knu.ac.kr (EK Park); syukim@knu.ac.kr (SY Kim)
}

\section{Accepted 31 August 2006}

Abbreviations: BMD, bone mineral density; BMl, body mass index; Hcy, homocysteine; ht, haplotype; MTRR, methionine synthase reductase; YSM, years since menopause

\begin{abstract}
Homocysteine (Hcy) is thought to play an important role in the development of osteoporosis and fracture. Methionine synthase reductase (MTRR) is an enzyme involved in the conversion of Hcy to methionine. We hypothesized that certain genetic polymorphisms of MTRR leading to reduced enzyme activity may cause hyperhomocysteinemia and affect bone metabolism. We therefore examined the associations of the A66G and C524T polymorphisms of the MTRR gene with bone mineral density (BMD) and serum osteocalcin levels in postmenopausal women. Although we did not detect any significant asso-
\end{abstract}

ciations between MTRR polymorphisms and BMD or serum osteocalcin levels, we found that the 66G/524C haplotype, which has reduced enzyme activity, was significantly associated with serum osteocalcin levels in a gene-dose dependent manner $(P=0.002)$. That is, the highest osteocalcin levels $(34.5 \pm 16.8 \mathrm{ng} / \mathrm{ml})$ were observed in subjects bearing two copies, intermediate osteocalcin levels $(32.6 \pm 14.4 \mathrm{ng} / \mathrm{ml})$ were observed in subjects bearing one copy, and the lowest levels of osteocalcin $(28.8 \pm 10.9 \mathrm{ng} / \mathrm{ml})$ were observed in subjects bearing no copies. These results suggest that the $66 \mathrm{G} / 524 \mathrm{C}$ haplotype of the MTRR gene affect bone turn over rate.

Keywords: bone density; methionine synthase reductase; osteocalcin; polymorphism; postmenopause

\section{Introduction}

Hyperhomocysteinemia has been reported to be an independent risk factor for osteoporotic fractures, cardiovascular disease and cancer (Song et al., 2001; Wald et al., 2002; Gilfix, 2003; Lee et al., 2004; McLean et al., 2004; van Meurs et al., 2004; Sato et al., 2005). Treatment with vitamin B12 and folate, which lower Hcy levels, has been found to markedly decrease the risk of hip fracture in stroke patients (Sato et al., 2005), indicating that Hcy may play an important role in the development of osteoporosis. Although the precise mechanisms of Hcy-induced osteoporosis has not been determined, interfering with collagen cross-linking (Lubec et al., 1996), increased osteoclastic bone resorption (Herrmann et al., 2005) and decreased osteoblastic bone formation (Kim et al., 2006), have been reported to contribute to the development of Hcy- induced osteoporosis.

Hcy, an intermediate metabolite of methionine, is reconverted to methionine by the transfer of a methyl group from methylenetetrahydrofolate, a reduction catalyzed by the enzyme methionine synthase (Dimitrova et al., 2002). This remethylation process requires adequate levels of the cofactor, activated cobalamin, which are maintained by the enzyme MTRR. Thus reduced activity of MTRR should disturb the remethylation of Hcy resulting in hyperhomocysteinemia. Indeed, a genetic defect in MTRR has been detected in patients with homocystinuria, 
an inherited disorder of Hcy metabolism characterized by severe hyperhomocysteinemia and early onset of atherosclerosis and osteoporosis (Leclerc et al., 1998). Although the A66G and C524T genetic polymorphisms of MTRR have been reported to be associated with enzyme activity (Olteanu et al., 2002) and plasma Hcy concentration (Botto et al., 2003; Vaughn et al., 2004), the association of these polymorphisms with bone metabolism has not been determined. We therefore investigated the relationships between the A66G and C524T polymorphisms of MTRR gene and bone mineral density and serum osteocalcin levels in postmenopausal women.

\section{Materials and Methods}

\section{Subjects}

The study population consisted of 560 apparently healthy, postmenopausal women who had visited Asan Medical Center (Seoul, Korea) (Kim et al., 2005). In brief, menopause was defined as the absence of menstruation for at least 6 months, which was confirmed by a serum FSH concentration $>30$ IU/I. Women who were prematurely menopausal (under 40 years of age) were excluded. Subjects were also excluded if they had taken drugs, such as bisphosphonates, estrogen and thyroid hormones, that might affect bone metabolism for more than 6 months or within the previous 12 months, or if they had suffered from any disease, such as thyroid diseases, hyperparathyroidism and renal failure, that might affect bone metabolism. Women were also excluded if they had osteophytic formation above the fourth grade of the Nathan classification (Nathan et al., 1962), and/or severe facet joint osteoarthritis in the lumbar spine diagnosed using conventional spine radiographs. The study was approved by the Institutional Review of Board of Asan Medical Center, and written informed consent was obtained from each participant.

\section{BMD measurement}

BMD at the lumbar spine (L2-L4) and femoral neck was measured using dual-energy X-ray absorptiometry (Lunar, Expert XL, Madison, WI) in 431 women. In the remaining 129 women, BMD was measured using Hologic equipment (QDR 4500-A, Waltham, MA). The coefficients of variation (CV) for the Lunar and Hologic equipment were $0.82 \%$ and $0.85 \%$, respectively, for the lumbar spine and $1.12 \%$ and $1.20 \%$, respectively, for the femoral neck.
Table 1. PCR primers and probes used for MTRR genotyping.

\begin{tabular}{lll}
\hline Locus & Primer sequence (5'-3') \\
\hline A66G & Forward & AGCAGGGACAGGCAAAGG \\
& Reverse & GCAGAAAATCCATGTACCACAGCTT \\
& Probe-1 (VIC) & ATCGCAGAAGAAATATGTGA \\
& Probe-2 (FAM) & ATCGCAGAAGAAATGTGTGA \\
C524T & Forward & ACTCCCGGTGGCATCAC \\
& Reverse & ATGTGTAGCAGCTCTGACTTCAC \\
& Probe-1 (VIC) & CTGCATCCTCGAGGAC \\
& Probe-2 (FAM) & CTGCATCCTTGAGGAC \\
\hline
\end{tabular}

\section{Measurement of serum osteocalcin levels}

Fasting venous blood samples were obtained between 8 and 10 A.M. and centrifuged, and the sera were stored at $-80^{\circ} \mathrm{C}$ until assayed. Serum osteocalcin concentrations were determined using an immunoradiometric assay kit (OSTEO-RIACT, $\mathrm{CIS}$ bio international, France). The mean inter-assay $\mathrm{CV}$ was $2.8 \%$, and the mean intra-assay $\mathrm{CV}$ was $5.2 \%$.

\section{Genotyping analysis}

Genomic DNA was extracted from peripheral blood leukocytes using a Wizard Genomic DNA purification kit (Promega, Madison, WI). For genotyping of the MTRR gene (Ref. Seq. of MTRR mRNA: NM 002454 and contig: NT_006576), PCR primers and probes were designed by Primer Express (Applied Biosystems, Foster City, CA) (Table 1). One allelic probe was labeled with the FAM dye and the other with the fluorescent VIC dye. PCR reaction were performed in a 384-well format in TaqMan Universal Master mix without UNG (Applied Biosystems), in a total reaction volume of $5 \mu$ l using $20 \mathrm{ng}$ of genomic DNA, PCR primer concentrations of $900 \mathrm{nM}$ and TaqMan MGB-probe concentrations of $200 \mathrm{nM}$. The plates were placed in a PE 977 thermal cycler (Applied Biosystems) and heated at $50^{\circ} \mathrm{C}$ for $2 \mathrm{~min}$ and $95^{\circ} \mathrm{C}$ for $10 \mathrm{~min}$ followed by 40 cycles of $95^{\circ} \mathrm{C}$ for $15 \mathrm{sec}$ and $60^{\circ} \mathrm{C}$ for $1 \mathrm{~min}$. The TaqMan assay plates were transferred to a Prism 7900HT instrument (Applied Biosystems) where the fluorescence intensity in each well of the plate was read. Fluorescence data files from each plate were analyzed using automated software (SDS 2.1; Applied Biosystems).

\section{Statistics}

$\chi^{2}$ tests were used to determine whether individual variants at each locus were in Hardy-Weinberg equilibrium in the population. We exmamined Le- 
wontin's $D^{\prime}\left(\left|D^{\prime}\right|\right)$ and the linkage disequlibrium coefficient, r2, between the biallelic loci (Hedrick, 1987; Hedrick et al., 2001).

Haplotypes (ht) of each individual were inferred using the algorithm (PHASE; Stephens et al., 2001) which uses a Bayesian approach incorporating a priori expectations of haplotypic structure based on population genetics and coalescent theory. Phase probabilities of all polymorphic sites for haplotypes were calculated for each individual using this software. Individuals with phase probabilities of less than $97 \%$ were excluded in analysis. The genetic effects of inferred haplotypes were analyzed in the same way as polymorphisms. Multiple regression analyses were performed for BMD controlling for age (continuous variable), years since menopause (YSM; continuous variable), weight, height, and type of bone densitometer as covariates, and osteocalcin controlling for age (continuous variable), YSM (continuous variable), weight and height. A value of $P<0.05$ was considered statistically significant.

\section{Results}

The mean age, height, weight, body mass index (BMI) and YSM of the subjects were $59.4 \pm 7.2$ years (range 46-83 years), $154.8 \pm 5.3 \mathrm{~cm}, 56.5 \pm$ $7.4 \mathrm{~kg}, 23.6 \pm 2.9 \mathrm{~kg} / \mathrm{m}^{2}$ and $10.4 \pm 8.2$ years (range 1-35 years), respectively. As expected, the age, YSM, weight, and height were each significantly correlated with BMD at both the lumbar spine and femoral neck (Table 2). BMD measured by Lunar equipment $\left(0.870 \pm 0.182 \mathrm{~g} / \mathrm{cm}^{2}\right.$ at the lumbar spine and $0.723 \pm 0.128 \mathrm{~g} / \mathrm{cm}^{2}$ at the femoral neck) was significantly higher than BMD measured by Hologic equipment $\left(0.764 \pm 0.116 \mathrm{~g} / \mathrm{cm}^{2}\right.$ at the lumbar spine and $0.606 \pm 0.098 \mathrm{~g} / \mathrm{cm}^{2}$ at the femoral neck. $P<$ 0.0001 for each). Therefore, we added the type of the densitometry as a covariate during statistical analysis (Kim et al., 2005). As previously described (Cifuentes et al., 2003) body weight was found to be negatively correlated with serum osteocalcin levels (Table 2) and was included as a covariate for statistical analysis. Regression analysis revealed that MTRR polymorphisms showed no association with BMI.

The frequencies of variant alleles for the A66G and C524T polymorphisms were 0.29 and 0.13 , respectively. The polymorphisms were in Hardy-Weinberg equilibrium. Two sites were not in linkage disequilibrium $\left(r^{2}=0.156\right.$, linkage disequilibrium coefficient $=0.637$ ). The frequency of the $66 \mathrm{G}$ allele was significantly lower than observed in Caucasian subjects (0.29 vs. 0.5; Wilson et al., 1999).

We analyzed the associations between BMD and these polymorphisms after adjustment for age, YSM, weight, height and type of bone densitometer (Table 3 ). We found, however, that neither polymorphism was associated with BMD at the lumbar spine and femoral neck. Although we observed weak associations between the A66G and C524T alleles and serum osteocalcin concentrations, these associations were not significant (Table 4).

Since the haplotype, including $66 \mathrm{G} / 524 \mathrm{C}$ alleles (frequency 0.19 ), was reported to be associated with

Table 2. Clinical profiles and multiple regression analyses of BMD

\begin{tabular}{|c|c|c|c|c|c|c|c|c|c|c|}
\hline \multicolumn{2}{|c|}{ Clinical profiles } & \multicolumn{3}{|c|}{ Lumbar spine BMD } & \multicolumn{3}{|c|}{ Femoral neck BMD } & \multicolumn{3}{|c|}{ Osteocalcin } \\
\hline Variables & Mean \pm SD & $\beta$ & SE & $P$ & $\beta$ & SE & $P$ & $\beta$ & SE & $P$ \\
\hline Age (years) & $59.4 \pm 7.2$ & -0.004 & 0.002 & 0.01 & -0.003 & 0.001 & 0.005 & -0.310 & 0.172 & 0.07 \\
\hline Weight (kg) & $56.5 \pm 7.4$ & 0.006 & 0.001 & $<0.0001$ & 0.003 & 0.001 & $<0.001$ & -0.243 & 0.087 & 0.006 \\
\hline Height (cm) & $154.8 \pm 5.3$ & 0.003 & 0.001 & 0.013 & 0.002 & 0.001 & 0.09 & 0.203 & 0.131 & 0.12 \\
\hline YSM (years) & $10.4 \pm 8.2$ & -0.003 & 0.002 & 0.02 & -0.005 & 0.001 & $<0.001$ & 0.265 & 0.152 & 0.08 \\
\hline Densitometer & - & -0.125 & 0.015 & $<0.001$ & -0.135 & 0.010 & $<0.001$ & & & \\
\hline \multicolumn{11}{|l|}{$\begin{array}{l}\text { Spine BMD } \\
\left(\mathrm{g} / \mathrm{cm}^{2}\right)\end{array}$} \\
\hline Lunar $(431)^{a}$ & $0.870 \pm 0.182$ & & & & & & & & & \\
\hline Hologic (129) ${ }^{a}$ & $0.764 \pm 0.116$ & & & & & & & & & \\
\hline \multicolumn{11}{|c|}{$\begin{array}{l}\text { Femoral neck BMD } \\
\left(\mathrm{g} / \mathrm{cm}^{2}\right)\end{array}$} \\
\hline Lunar & $0.723 \pm 0.128$ & & & & & & & & & \\
\hline Hologic & $0.606 \pm 0.098$ & \multicolumn{3}{|c|}{$R^{2}=0.31$} & \multicolumn{3}{|c|}{$R^{2}=0.45$} & \multicolumn{3}{|c|}{$R^{2}=0.028$} \\
\hline
\end{tabular}

${ }^{\mathrm{a}}$ Number of subjects who received BMD examination by each densitometer. 
Table 3. Lumbar spine and femoral neck BMD $\left(\mathrm{g} / \mathrm{cm}^{2}\right)$ relative to MTRR genotype.

\begin{tabular}{|c|c|c|c|c|c|c|c|c|}
\hline \multirow{2}{*}{ Locus } & \multicolumn{4}{|c|}{ Lumbar spine BMD $\left(\mathrm{g} / \mathrm{cm}^{2}\right)$} & \multicolumn{4}{|c|}{ Femoral neck BMD $\left(\mathrm{g} / \mathrm{cm}^{2}\right)$} \\
\hline & $\mathrm{C} / \mathrm{C}^{*}$ & $\mathrm{C} / \mathrm{R}$ & $\mathrm{R} / \mathrm{R}$ & $P$ & $\mathrm{C} / \mathrm{C}$ & $\mathrm{C} / \mathrm{R}$ & $\mathrm{R} / \mathrm{R}$ & $P$ \\
\hline A66G & $0.85 \pm 0.17(281)$ & $0.85 \pm 0.18(232)$ & $0.84 \pm 0.20(42)$ & NS & $0.70 \pm 0.13$ & $0.7 \pm 0.13$ & $0.69 \pm 0.14$ & NS \\
\hline C524T & $0.85 \pm 0.16(413)$ & $0.84 \pm 0.20(135)$ & $0.84 \pm 0.17(7)$ & NS & $0.69 \pm 0.13$ & $0.7 \pm 0.14$ & $0.73 \pm 0.15$ & NS \\
\hline $66 G / 524 C$ & $0.85 \pm 0.17(362)$ & $0.85 \pm 0.17(177)$ & $0.84 \pm 0.2(16)$ & NS & $0.70 \pm 0.13$ & $0.70 \pm 0.13$ & $0.66 \pm 0.16$ & NS \\
\hline
\end{tabular}

Data adjusted for age, years since menopause, weight, height, and densitometry. All results presented as mean $\pm \mathrm{SD}$ (number of subjects). ${ }^{*} \mathrm{C} / \mathrm{C}$, $\mathrm{C} / \mathrm{R}$, and $\mathrm{R} / \mathrm{R}$ represent homozygotes for the common allele, heterozygotes and homozygotes for the rare allele, respectively.

Table 4. Serum osteocalcin levels $(\mathrm{ng} / \mathrm{ml})$ relative to MTRR genotype.

\begin{tabular}{|c|c|c|c|c|}
\hline \multirow{2}{*}{ Locus } & \multicolumn{3}{|c|}{ Genotype } & \multirow{2}{*}{$P$ value } \\
\hline & $C / C^{*}$ & $\mathrm{C} / \mathrm{R}$ & $\mathrm{R} / \mathrm{R}$ & \\
\hline A66G & $29.3 \pm 11.4(220)$ & $30.9 \pm 13.3(168)$ & $32.1 \pm 14.3(31)$ & NS \\
\hline C524T & $30.6 \pm 13.0(315)$ & $29.1 \pm 10.4(98)$ & $24.5 \pm 6.5(6)$ & NS \\
\hline $66 \mathrm{G} / 524 \mathrm{C}$ & $28.8 \pm 10.9(282)$ & $32.6 \pm 14.4(122)$ & $34.5 \pm 16.8(15)$ & $0.002^{\dagger}$ \\
\hline
\end{tabular}

Data adjusted for weight. All results presented as mean $\pm S D$ (number of subjects). ${ }^{*} \mathrm{C} / \mathrm{C}, \mathrm{C} / \mathrm{R}$, and $\mathrm{R} / \mathrm{R}$ represent homozygotes for the common allele, heterozygotes and homozygotes for the rare allele, respectively. ${ }^{\dagger} P$ value for both codominant and dominant model.

reduced enzyme activity (Olteanu et al., 2002), we examined the association of this haplotype with BMD and osteocalcin concentration. Although we observed no difference in BMD at the lumbar spine and femoral neck according to the haplotype (Table $3)$, we observed an association between this haplotype and serum osteocalcin levels $(P=0.002$ in both codominant and dominant models) in a gene-dose dependent manner. That is, the highest osteocalcin concentrations $(34.5 \pm 16.8 \mathrm{ng} / \mathrm{ml})$ were detected in individuals bearing two copies of this haplotype, intermediate levels $(32.6 \pm 14.4 \mathrm{ng} / \mathrm{ml})$ were detected in subjects bearing one copy, and the lowest levels $(28.8 \pm 10.9 \mathrm{ng} / \mathrm{ml})$ were observed in subjects bearing no copies (Table 4 ).

\section{Discussion}

In relation to Hcy-induced osteoporosis, some studies (Miyao et al., 2000; Abrahamsen et al., 2003; Bathum et al., 2004; Villadsen et al., 2005) have reported that the $\mathrm{C677T}$ polymorphism of the gene encoding methylenetetrahydrofolate reductase, which catalyzes the conversion of 5,10-methylenetetrahydrofolate to 5-methylenetetrahydrofolate, the substrate for Hcy methylation, was associated with osteoporosis and increased fracture risk. However, to our knowledge, an association between the polymorphisms of MTRR gene and bone metabolism has not been reported.
We have shown here that the MTRR haplotype $(66 \mathrm{G} / 524 \mathrm{C})$ is associated with serum osteocalcin concentrations in postmenopausal women. Although neither polymorphism was significantly associated with BMD and serum osteocalcin levels, we observed trends between these MTRR polymorphisms and osteocalcin concentrations. Specifically, subjects with the $66 \mathrm{G}$ and $524 \mathrm{C}$ alleles had higher serum osteocalcin levels than those with the $66 \mathrm{~A}$ and 524T alleles, respectively. The positive association of the $66 \mathrm{G} / 524 \mathrm{C}$ haplotype with osteocalcin levels may result from the sum of the modest effects of each individual allele on bone metabolism.

$M T R R$ is a dual flavoprotein that catalyses the conversion of cob(II)alamin into methyl-cob(III)ala$\mathrm{min}$, the cofactor of methionine synthase (Olteanu et al., 2001; 2002). FAD (flavin adenine dinucleotide) and FMN (flavin mononucleotide) facilitate electron transfer from NADPH to cob(II)alamin during reductive methylation. This reductive methylation of cob(II)alamin may serve to maintain methionine synthase in its active form. The A66G and C524T sequence variants change the coding sequence from isoleucine to methionine (lle22Met) and from serine to leucine (Ser175Leu), respectively. The A66G variant is located in the FMN domain and may therefore interact with methionine synthase (Hall et al., 2000; 2001). Although we did not measure plasma Hcy levels, the $66 \mathrm{G} / 524 \mathrm{C}$ haplotype was found to have 4-fold lower enzyme activity than wild type (Olteanu et al., 2002) and the $66 \mathrm{G}$ allele has 
been reported to be associated with higher plasma Hcy concentrations (Botto et al., 2003; Vaughn et al., 2004). Our finding, demonstrating that the 66G/524C haplotype was associated with higher osteocalcin concentrations, further supports that hyperhomocysteinemia is associated with higher osteocalcin levels (Dhonukshe-Rutten et al., 2005).

Osteocalcin is a product of osteoblasts that is considered a marker of bone formation (Brown et al., 1984). However, osteocalcin is also released from bone matrix into blood during bone resorption, suggesting that osteocalcin is also a marker of bone turnover (Delmas et al., 1990; Page et al., 1993; Ivaska et al., 2004). Thus the higher serum osteocalcin levels observed in individuals with the $66 \mathrm{G} / 524 \mathrm{C}$ haplotype may reflect increased bone turnover rather than simply increased bone formation and thus may be associated with an increased risk of fracture (Garnero et al., 1996).

Osteoporosis is a skeletal disorder characterized by compromised bone strength, which predisposes individuals to an increased risk of fracture $(\mathrm{NIH}$ Consensus Development Panel on Osteoporosis Prevention, Diagnosis, and Therapy, 2001). In patients with homocystinuria, severe hyperhomocysteinemia is associated with very low bone mass (Parrot et al., 2000). In the general population, mild to moderate hyperhomocysteinemia is associated with an increased risk of fracture (McLean et al., 2004; van Meurs et al., 2004; Sato et al., 2005), but not with BMD, suggesting that mild to moderate increases in Hcy concentration may compromise bone strength by reducing bone quality rather than bone density. This may explain, at least in part, the lack of association between MTRR polymorphisms and BMD.

This study has some limitations. Since serum Hcy concentration was not measured in our study subjects, we could not document a direct association between the MTRR $66 \mathrm{G} / 524 \mathrm{H}$ haplotype and serum homocysteine concentration. However, previous studies, demonstrating an association of MTRR 66G/ $524 \mathrm{H}$ haplotype with low enzyme activity and thus high plasma Hcy level, suggest that this haplotype has a functional relevance in regulation of Hcy levels in plasma. We did not measure the concentration of other biochemical markers of bone turnover. Measurement of other specific bone turnover markers would support the relationship between MTRR haplotype and bone metabolism. In addition, we did not measure the serum concentrations of vitamin B12 and folate concentration. Since the effect of the A66G polymorphism of MTRR would be more pronounced in subjects with low cobalamin levels (Wilson et al., 1999), our results assume no difference in cobalamin and folate concentrations.
In conclusion, we found that the $66 \mathrm{G} / 524 \mathrm{C}$ haplotype of the MTRR gene was associated with serum osteocalcin concentrations in postmenopausal women, suggesting that this haplotype may affect bone turnover rate.

\section{Acknowledgement}

This study was supported by a grant from the Korea Health 21 R\&D Project, Ministry of Health \& Welfare, Republic of Korea (Project No A010252).

\section{References}

Abrahamsen B, Madsen JS, Tofteng CL, Stilgren L, Bladbjerg EM, Kristensen SR, Brixen K, Mosekilde L. A common methylenetetrahydrofolate reductase (C677T) polymorphism is associated with low bone mineral density and increased fracture incidence after menopause: longitudinal data from the Danish osteoporosis prevention study. J Bone Miner Res 2003;18:723-9

Bathum L, von Bornemann Hjelmborg J, Christiansen L, Madsen JS, Skytthe A, Christensen K. Evidence for an association of methylene tetrahydrofolate reductase polymorphism C677T and an increased risk of fractures: results from a population-based Danish twin study. Osteoporos Int 2004;15:659-64

Botto N, Andreassi MG, Manfredi S, Masetti S, Cocci F, Colombo MG, Storti S, Rizza A, Biagini A. Genetic polymorphisms in folate and homocysteine metabolism as risk factors for DNA damage. Eur J Hum Genet 2003;11:671-8

Brown JP, Delmas PD, Malaval L, Edouard C, Chapuy MC, Meunier PJ. Serum bone Gla-protein: a specific marker for bone formation in postmenopausal osteoporosis. Lancet 1984;1:1091-3

Cifuentes M, Johnson MA, Lewis RD, Heymsfield SB, Chowdhury HA, Modlesky CM, Shapses SA. Bone turnover and body weight relationships differ in normal-weight compared with heavier postmenopausal women. Osteoporos Int 2003;14: 116-22

Delmas PD, Christiansen C, Mann KG, Price PA. Bone Gla protein (osteocalcin) assay standardization report. J Bone Miner Res 1990;5:5-11

Dhonukshe-Rutten RA, Pluijm SM, de Groot LC, Lipis P, Smit $\mathrm{JH}$, van Staveren WA. Homocysteine and vitamin B12 status relate to bone turnover markers, broadband ultrasound attnenuation, and fractures in healthy elderly people. J Bone Miner Res 2005;20:921-9

Dimitrova KR, DeGroot K, Myers AK, Kim YD. Estrogen and homocysteine. Cardiovas Res 2002;53:577-88

Garnero P, Sornay-Rendu E, Chapuy MC, Delmas PD. Increased bone turnover in late postmenopausal women is a major determinant of osteoporosis. J Bone Miner Res 1996;11:337-49

Gilfix BM. Hyperhomocysteinemia: genetic determinants and selected mouse models. Clin Invest Med 2003;26:121-32 
Hall DA, Jordan-Starck TC, Loo RO, Ludwig ML, Matthews RG. Interaction of flavodoxin with cobalamin-dependent methionine synthase. Biochemistry 2000;39:10711-9

Hall DA, Vander Kooi CW, Stasik CN, Stevens SY, Zuiderweg ER, Matthews RG. Mapping the interaction between flovodoxin and its physiological partners flavodoxin reductase and cobalamin-dependent methionine synthase. Proc Natl Acad Sci USA 2001;98:9521-6

Hedrick PW. Gametic disequlibrium measures: proceed with caution. Genetics 1987;117:331-41

Hedrick $\mathrm{P}$, Kumar $\mathrm{S}$. Mutation and linkage disequlibrium in human mtDNA. Eur J Hum Genet 2001;9:969-72

Herrmann M, Widmann T, Colaianni G, Colucci S, Zallone A, Herrmann W. Increased osteoclast activity in the presence of increased homocysteine concentrations. Clin Chem 2005; $51: 2348-53$

Ivaska KK, Hentunen TA, Vääräniemi J, Ylipahkala H, Pettersson K, Väänänen HK. Release of intact and fragmented osteocalcin molecules from bone matrix during bone resorption in vitro. J Biol Chem 2004;279:18361-9

Kim DJ, Koh JM, Lee O, Kim NJ, Lee YS, Kim YS, Park JY, Lee KU, Kim GS. Homocysteine enhances apoptosis in human bone marrow stromal cells. Bone 2006 Apr 24; [Epub ahead of print]

Kim GS, Koh JM, Chang JS, Park BL, Kim LH, Park EK, Kim SY, Shin HD. Association of the OSCAR promoter polymorphism with BMD in postmenopausal women. J Bone Miner Res 2005;20:1342-8

Leclerc D, Wilson A, Dumas R, Gafuik C, Song D, Watkins D, Heng HH, Rommens JM, Scherer SW, Rosenblatt DS, Gravel RA. Cloning and mapping of a cDNA for methionine synthase reductase, a flavoprotein defective in patients with homocystinuria. Proc Natl Acad Sci USA 1998;95:3059-64

Lee SA, Kang D, Nishio H, Lee MJ, Kim DH, Han W, Yoo KY, Ahn SH, Choe KJ, Hirvonen A, Noh DY. Methylenetetrahydrofolate reductase polymorphism, diet, and breast cancer in Korean women. Exp Mol Med 2004;36:116-21

Lubec B, Fang-Kircher S, Lubec T, Blom HJ, Boers GH. Evidence for McKusick's hypothesis of deficient collagen cross-linking in patients with homocystinuria. Biochim Biophys Acta 1996;1315:159-62

McLean RR, Jacques PF, Selhub J, Tucker KL, Samelson EJ, Broe KE, Hannan MT, Cupples LA, Kiel DP. Homocysteine as a predictive factor for hip fracture in older persons. N Engl J Med 2004;350:2042-9

Miyao M, Morita H, Hosoi T, Kurihara H, Inoue S, Hoshino S, Shiraki M, Yazaki Y, Ouchi Y. Association of methylenetetrahydrofolate reductase (MTHFR) polymorphism with bone mineral density in postmenopausal Japanese women. Calcif Tissue Int 2000;66:190-4

Nathan $\mathrm{H}$. Osteophytes of the vertebral column: an anatomical study of their development according to age, race, and sex with considerations as to their etiology and significance. J Bone Joint Surg Am 1962;44A:243-68
NIH Consensus Development Panel on Osteoporosis Prevention, Diagnosis, and Therapy. Osteoporosis Prevention, Diagnosis, and Therapy. JAMA 2001;285:785-95

Olteanu H, Banerjee R. Human methionine synthase reductase, a soluble P-450 reductase-like dual flavoprotein, is sufficient for NADPH-dependent methionine synthase activation. J Biol Chem 2001;38:35558-63

Olteanu H, Munson T, Banerjee R. Differences in the efficiency of reductive activation of methionine synthase and exogenous electron acceptors between the common polymorphic variants of human methionine synthase reductase. Biochemistry 2002;41:13378-85

Page AE, Hayman AR, Andersson LMB, Chambers TJ, Warburton MJ. Degradation of bone matrix proteins by osteoclast cathepsins. Int J Biochem 1993;25:545-50

Parrot F, Redonnet-Vernhet I, Lacombe D, Gin H. Osteoporosis in late-diagnosed adult homocystinuric patients. J Inherit Metab Dis 2000;23:338-40

Sato Y, Honda Y, Iwamoto J, Kanoko T, Satoh K. Effect of folate and mecobalamin on hip fractures in patients with stroke: a ramdomized controlled trial. JAMA 2005;293:1082-8

Song KS, Song JW, Choi JR, Kim HK, Shin JS, Kim JH. Homozygous V/V (677C to T) and D/D (2756G to A) variants in the methylenetetrahydrofolate and methionine synthase genes in a case of hyperhomocysteinemia with stroke at young age. Exp Mol Med 2001;33:106-9

Stephens M, Smith NJ, Donnelly P. A new statistical method for haplotype reconstruction from population data. Am J Hum Genet 2001;68:978-89

van Meurs JB, Dhonukshe-Rutten RA, Pluijm SM, van der Klift $M$, de Jonge $R$, Lindemans $J$, de Groot LC, Hofman $A$, Witteman JC, van Leeuwen JP, Breteler MM, Lips P, Pols HA, Uitterlinden AG. Homocysteine levels and the risk of osteoporotic fracture. N Engl J Med 2004;350:2033-41

Vaughn JD, Bailey LB, Shelnutt KP, Dunwoody KM, Maneval DR, Davis SR, Quinlivan EP, Gregory JF 3rd, Theriaque DW, Kauwell GP. Methionine synthase reductase $66 \mathrm{~A} \rightarrow \mathrm{G}$ polymorphism is associated with increased plasma homocysteine concentration when combined with the homozygous methylenetetrahydrofolate reductase $677 \mathrm{C} \rightarrow \mathrm{T}$ variant. J Nutr 2004;134:2985-90

Villadsen MM, Bunger MH, Carstens M, Stenkjaer L, Langdahl BL. Methylenetetrahydrofolate reductase (MTHFR) C677T polymorphism is associated with osteoporotic vertebral fractures, but is a weak predictor of BMD. Osteoporos Int 2005; 16:411-6

Wald DS, Law M, Morris JK. Homocysteine and cardiovascular disease: evidence on causality from a meta-analysis. BMJ 2002;325:1202

Wilson A, Platt R, Wu Q, Leclerc D, Christensen B, Yang H, Gravel RA, Rozen R. A common variant in methionine synthase reductase combined with low cobalamin (vitamin B12) increases risk for spina bifida. Mol Genet Metab 1999; $67: 317-23$ 